\title{
A OFICINA MOMENTO DE LEITURA EM UMA ESCOLA DE TEMPO INTEGRAL NO MUNICÍPIO DE ARIQUEMES (RO): Contextos e Pretextos
}

\section{THE OFFICEMOMENT OF READING IN A SCHOOL OF COMPREHENSIVE TIME IN THE MUNICIPALITY OF ARIQUEMES (RO): Contexts and Pretexts}

\author{
Silvana de Fátima dos Santos \\ Pró-Licenciatura em Educação Física (UNB/ \\ UNIR) \\ E-mail: silvanasantos.ped@gmail.com \\ Eliane de Araújo Teixeira \\ Escola Ireno Antonio Berticelli (SED - \\ Rondônia) \\ E-mail: elianeteixeira_25@hotmail.com \\ Francisco Roberto da Silva de Carvalho \\ Técnico em Assuntos Educacionais do \\ Instituto Federal de Educação Ciência e \\ Tecnologia de Mato Grosso do Sul - IFMS - \\ Campus Naviraí \\ E-mail: francisco.carvalho@ifms.edu.br
}

\section{INTRODUÇÃOO}

organização efetiva do trabalho escolar voltado para o desenvolvimento
da leitura nos anos iniciais do ensino fundamental é uma tarefa pedagógica essencial nesta etapa de ensino. O ato de ler está diretamente interligado à autonomia do aluno, ao alargamento de suas percepções. Ao relacionar o lido com suas vivências cotidianas, o sujeito não só se apropria de informações, mas de possibilidades para a construção de conhecimentos.

Assim, desenvolver um trabalho intencional que vá além da decodificação de signos, mas que tenha como centralidade as conjunturas que subsidiam o ato de ler, considerando esta ação como uma interlocução expressiva 
entre o aluno, a proposta escolar e a realidade que o rodeia, torna-se um desafio, uma vez que a organização do trabalho escolar é imbricado de inferências que perpassam desde a concepção de leitura apregoada na instituição escolar, a formação docente, as condições materiais e de infraestruturas disponíveis para sua implementação, até aspectos culturais e sociais dos alunos.

O presente estudo resulta da investigação acerca da organização de uma escola e o desenvolvimento efetivo da oficina curricular Momento de Leitura. Esse componente curricular agrega 160 horas anuais e faz parte do Projeto Burareiro de Educação em Tempo Integral e direciona a ampliação do currículo e do tempo de permanência de alunos e servidores em uma escola pertencentes à Secretaria Municipal de Educação de Ariquemes (RO) desde 2008. A pesquisa foi norteada pelas indagações: qual a concepção de educação integral que norteia a implantação do projeto na rede municipal de ensino? Quais as condições efetivas em que a oficina curricular Momento de Leitura tem sido desenvolvida na instituição analisada?

O objetivo da pesquisa conduziu à análise de fatores que implicam na organização escolar e no desenvolvimento do trabalho pedagógico realizado na oficina Momento de Leitura, como componente curricular obrigatório de 1으 ao 5을 Ano do Ensino Fundamental.

Quanto aos procedimentos, a investigação configura-se como uma pesquisa documental e recorre à observação empírica para subsidiar a compreensão dos fenômenos. A análise documental envolveu o estudo de documentos institucionais, a análise de registros como fotografias, atas de reuniões e as orientações que norteiam a ampliação do tempo escolar nas escolas da rede municipal de ensino. Para isso, fez-se um estudo do manual do Projeto Burareiro de Educação em Tempo Integral (2013), em busca de se constatar de que modo está organizada a proposta de ampliação do tempo, de currículo escolar e os pressupostos que subsidiam a concepção de educação e as orientações para a Oficina Momento de Leitura. Analisou-se o Projeto Político Pedagógico (PPP) da escola a fim de situar de que modo tem se organizado a matriz curricular dessa instituição de ensino e a viabilidade da proposta de trabalho voltada para o desenvolvimento da leitura. Mediante a objetividade da proposta de trabalho com leitura propiciado pela Oficina Momento de Leitura, fez-se uma análise do plano de ensino da respectiva oficina, identificando suas aspirações comparadas à prática docente. Quanto aos docu- 
mentos norteadores e normatizadores que preveem ampliação do tempo e do currículo da escolas públicas, recorreu-se à Constituição Federal (CF) de 1988; ao Plano Nacional de Educação (PNE) 2014 - 2024; à Lei de Diretrizes e Bases da Educação Nacional (LDB) no 9394/96.

A investigação empírica ocorreu no decorrer do ano letivo de 2018. Foram realizadas observações do desenvolvimento da oficina, subsidiada pela observação do espaço físico e as condições de infraestrutura.

\section{AMPLIAÇÃO DO TEMPO ESCOLAR: Contextos e desafios atuais}

Embora a ampliação da jornada escolar brasileira tenha sua gênese na década de 1930, com o movimento escolanovista, sua expansão só ocorre mais tardiamente, com o alastramento das políticas neoliberais e as reformas de Estado.

No final do século XX, a ampliação do tempo escolar é fortalecida com a promulgação da Constituição Federal (CF) de 1988, apresenta em seu Art. 205 a educação como "[...] direito de todos, será promovida e incentivada com a colaboração da sociedade, visando ao pleno desenvolvimento da pessoa, seu preparo para o exercício da cidadania" (BRASIL, 1988, p. 70).

Desse modo, a atual CF ao mesmo tempo que representa um avanço à educação brasileira, ao referendar a educação como direito social, suprime a o papel do Estado diante dessa tarefa de ser a instituição responsável e promotora por zelar por essa garantia, e atribui a responsabilidade educacional à sociedade, não esclarecendo de que modo se efetivará a colaboração social e a responsabilidade de incentivar e promover essa educação.

A atual LDB, Lei no 9394/96, prevê a autonomia dos estabelecimentos de ensino para a ampliação da jornada escolar, consagrada no Art.34, a qual enfatiza que: "[...] a jornada escolar no ensino fundamental incluirá pelo menos quatro horas de trabalho efetivo em sala de aula, sendo progressivamente ampliado o período de permanência na escola". E prossegue: "serão conjugados todos os esforços objetivando a progressão das redes escolares públicas urbanas de ensino fundamental para o regime de escolas de tempo integral" (BRASIL, 1996, p. 28). 
Recentemente, o atual Plano Nacional de Educação (PNE) 2014-2024, documento norteador do ensino, explicita, dentre suas metas, a ampliação da jornada escolar e prevê a implantação de tempo integral em cinquenta por cento das escolas públicas de educação básica até 2024. De acordo com dados estatísticos disponibilizados pelo Instituto Nacional de Estudos e Pesquisas Educacionais Anísio Teixeira (INEP), em 2012 eram 28,3\% das instituições públicas de ensino atendiam pelo menos uma matrícula em tempo integral. Esse índice elevou para 44,2\% em 2015, um avanço de 15,9\%.

Ao se analisar os dados de ampliação do tempo escolar na região Norte do país, em comparação às demais regiões brasileiras, pode-se constatar que, seja pela sua extensão geográfica e número de habitantes, seja pelos recursos de financiamento ou carência de iniciativas governamentais, demonstra o menor índice de escola com matrículas em tempo integral. No entanto, conforme os dados analisados, no período de 2012 a 2015 o número de instituições com matrículas em tempo integral mais que dobrou, indo de $13,6 \%$ para $31,0 \%$, o que representa um crescimento de $17,4 \%$.

Apesar de o fato dos dados apontarem avanços significativos no número de estabelecimentos de ensino que atendem em tempo integral, as condições em que essas propostas de ampliação de tempo escolar e em que o currículo ampliado se materializa nem sempre são questionadas.

Em Rondônia, o município de Ariquemes foi pioneiro na implantação de educação em tempo integral, com o Projeto Burareiro de Educação Integral' . Este projeto foi implementado em uma escola periférica da rede municipal de ensino, no ano letivo de 2005 e expandindo gradativamente a outras 4 escolas em 2008, atendendo a um total de 3.139 (três mil, cento e trinta e nove) estudantes neste ano.

Devidos aos desafios que foram se apresentado no decorrer dos anos, durante o ano letivo de 2018, o município possuía apenas 2 (duas) escolas nas quais é oferecido o Projeto Burareiro de Educação em Tempo Integral. Nesse ano de também foi publicado um decreto municipal tornando as ma-

1 De acordo com Frutuoso (2014), o projeto Burareiro de Educação Integral foi elaborado em 2005 para atender uma proposta da gestão municipal do período (2005-2008). Instituído pela Lei Municipal no 1.217/2006, este previa a implementação do Projeto no Ensino Fundamental, de forma gradativa, nas escolas urbanas do Sistema Municipal de Ensino de Ariquemes. No entanto, atingiu um números de 4 das 26 escolas municipais. 
trículas nestas duas instituições em tempo parcial ou integral, transformando a matrícula nas oficinas curriculares não obrigatórias, a critério dos responsáveis pelos alunos.

Dados disponibilizados pelo INEP, demonstram que no Brasil, no decorrer do ano letivo de 2017, aproximadamente $15,5 \%$ das matrículas realizadas na rede pública estadual e municipal foram efetivadas em tempo integral. Destas, 22,3\% são referentes aos anos iniciais do ensino fundamental, 16,1 $\%$ diz respeito aos anos finais do ensino fundamental e 8,1 \% ensino médio.

Quando analisamos os dados estatísticos referentes ao estado de Rondônia, percebe-se aspectos diferentes em relação à realidade nacional. Em $2017,7,6 \%$ das matrículas realizadas na rede estadual e municipal de ensino eram em tempo integral. Destas, $7,1 \%$ eram relacionadas aos anos iniciais do ensino fundamental, 5,8 \% aos anos iniciais do ensino fundamental e, diferentemente da realidade nacional, 9,9\% ensino médio.

Desse modo, percebe-se que ano letivo de $2017^{2}$, o município de Ariquemes $(\mathrm{RO})$ apresentou uma média de matrículas superior à média nacional, que é de 19,3\%. As matrículas nos anos iniciais do ensino fundamental representam 28,9\%; nos anos finais do ensino fundamental 7,9 \%e 21,1\% ensino médio.

De acordo com os dados apresentados, pode-se perceber que há um distanciamento entre o percentual de escolas que oferecem pelo menos uma matrícula em tempo integral e o percentual efetivo de alunos matriculados em tempo integral estatisticamente menor. Desse modo, como a meta 6 do Plano Nacional de Educação prevê o percentual de 50\% de instituições em atendimento em tempo integral, percebe-se que a centralidade da meta não tem como foco o atendimento ao aluno, mas o quantitativo de estabelecimentos, não se questionando as condições de infraestruturas dessas instituições, os recursos materiais e humanos disponíveis e, consequentemente nem a qualidade social dos programas implementados.

No entanto, a ampliação do tempo do aluno na escola necessita de elementos que vão além de expansão do currículo. Isso requer um olhar sobre

\footnotetext{
2 Apresenta-se dados referentes ao ano letivo de 2017 uma vez que eram os que estavam disponíveis para acesso no período da pesquisa.
} 
todas as dimensões que possibilitam e/ou são condições determinantes no desenvolvimento do processo.

Ao se referir aos elementos fundamentais a serem considerados na ampliação da jornada escolar, Cavalieri discorre sobre as condições organizativas de uma instituição em tempo integral, que implica "[...] além de definições curriculares compatíveis, toda uma infraestrutura precisa ser preparada do ponto de vista de espaços, dos profissionais e da organização do tempo" (2007, p. 1022-1023).

Tais condições organizativas, de infraestrutura e de recursos materiais e humanos são fundamentais para a garantia dos direitos à educação ao mesmo tempo em que dão suporte ao ato educativo, inerentes ao respeito dos direitos individuais e coletivos, uma vez que a escola perpassa a dimensão de loco de produção de conhecimento e se (re) dimensiona para atender as necessidades vitais dos sujeitos.

Para Leclerc e Moll, "a "integralidade" da política em questão não se constitui como algo que, por adição, venha alongar um todo que está curto ou compor um todo que existe a priori - nisso consiste o equívoco de se "oferecer mais do mesmo" (2012, p. 26), ou seja, a permanência em tempo integral precisa se apresentar e propor um diferencial na/para a vida dos alunos inseridos neste contexto. Caso contrário, ampliar o tempo sem um propósito claro e objetivo, sem que haja rupturas e transformação, torna-se uma decisão dispensável.

\section{A CONCEPÇÃO DE EDUCAÇÃO INTEGRAL NO PROJETO BURAREIRO: Percalços e retrocessos}

Ao se propor investigar sobre as condições concretas em que a oficina curricular Momento de Leitura tem se efetivado em uma escola da rede municipal de ensino, faz-se necessário o estudo da proposta que dá sustentabilidade à ampliação curricular investigada. Deste modo, ao se analisar as prescrições no manual do Projeto Burareiro de Educação Integral (2013), tem-se como pressuposto que a educação integral e consequentemente a ampliação curricular deve ter como centralidade as ações intencionais capazes de desenvolver as múltiplas potencialidades do sujeito a partir dos princípios da politecnia ou educação politécnica. 
Ao discorrer sobre em que consiste a politecnia ou educação politécnica, na obra intitulada Instruções aos Delegados do Conselho Central Provisório da Associação Internacional dos Trabalhadores, Marx elenca que está se dá respeitando os seguintes critérios:

Primeiramente: Educação mental [intelectual].

Segundo: Educação física, tal como é dada em escolas de ginástica e pelo exercício militar.

Terceiro: Instrução tecnológica, que transmite os princípios gerais de todos os processos de produção e, simultaneamente, inicia a sujeito e o jovem no uso prático e manejo dos instrumentos elementares de todos os ofícios (MARX, 1982, p. 5).

Ao prever a indissociabilidade entre educação intelectual, física e tecnológica, essas são tidas como condições inerentes para dar ao sujeito acesso ao patrimônio cultural produzido ao longo da história da humanidade, o conhecimento do próprio corpo, suas mudanças físicas e de seus limites, além do domínio de várias técnicas de produção, na qual o conhecimento seja visto não como fator de submissão do sujeito ao trabalho, mas como mecanismo de superação da dominação do sujeito.

Assim, afim de compreender a materialização do trabalho voltado para o desenvolvimento da leitura com alunos do $1^{\underline{0}}$ ao $5^{\underline{0}}$ ano, busca-se compreender o pressuposto políticos, pedagógicos e filosóficos que embasam essa proposta, onde consta (ou deveria constar) a gênese de sua fundamentação epistemológica e sua repercussão política e social.

Sabe-se que o sentido atribuído ao termo educação integral tem sido utilizado na educação com sentido polissêmico, sendo relacionado à educação desde a óptica restrita de ampliação do tempo até a organização escolar com contributos direcionados à formação humana o desenvolvimento de múltiplas potencialidades.

Ao se realizar a pesquisa documental, pode-se constatar que houve mudança, em 2013, da proposta piloto apresentada em 2005. Ao se referir à proposta apresentada para a implementação do projeto piloto, Maciel, Braga e Ranucci (2016) afirmam que os fins a serem alcançados pela mesma visavam: "[...] resgatar a memória histórico-cultural do Município e, ao mesmo 
tempo, oportunizar aos filhos das classes trabalhadoras uma educação de efetiva participação social e política" (p. 22).

Implantada no decorrer do ano letivo de 2005, essa proposta foi desenvolvida em uma escola periférica e com agravantes sociais, econômicos, culturais, políticos e de infraestrutura. A condução da ampliação do tempo e do currículo escolar deveriam ser conduzidos "[...] pela concepção de politecnia e fundamentada na pedagogia histórico-crítica, visando o desenvolvimento das múltiplas potencialidades humanas" (MACIEL; BRAGA; RANUCCI, 2016, p. 22).

Ao se comparar a proposta orientadora reformulada em 2013 pela Secretaria Municipal de Educação e a apresentada na obra Projeto Burareiro de Educação Integral: Original de Maciel, Braga e Ranucci (2016), pode-se constatar facilmente que o direcionamento filosófico, político e pedagógico assume outras dimensões.

No intuito de estender a implementação do Projeto a outras escolas públicas municipais, em junho de 2006, segundo registros da Secretaria Municipal de Educação, realizou uma avaliação das ações desenvolvidas na instituição piloto. Segundo o manual (2013), nesta avaliação foi constatado que ocorreram mudanças expressivas em determinados aspectos como: a diminuição das sujeitos que permaneciam na rua em horário oposto às aulas devido a permanência de maior tempo na escola com atividades recreativas, esportivas e culturais; a aproximação, a credibilidade e a confiança por parte dos responsáveis na instituição; a oferta de acompanhamento médico e dentário aos alunos que carecem desses serviços; a diminuição da evasão escolar, da agressividade e violência dos estudantes.

Contradizendo a própria avaliação que apontaram avanços significativos na realidade da escola onde a proposta inicial fora implantada, a Secretaria Municipal de Educação alegou necessidades de reformulação da Proposta inicial. Para isso, justificou que o documento norteador inicial carecia de um maior "aprofundamento" devido à:

[...] falta de conhecimento da proposta pedagógica do Projeto (Pedagogia histórico-crítica) e sua aplicabilidade no cotidiano escolar; estabelecimento de mecanismos que deem suporte à gestão democrática e participativa; infraestrutura deficitária e precária ao funcionamento do projeto; proposta curricular não 
condizente ao projeto; ampliação do envolvimento mais efetivo entre projeto e comunidade; planejamento integrado e participativo no âmbito escolar; necessidade de avaliação periódica; aperfeiçoamento profissional na perspectiva da Educação Integral, entre outros (2013, p. 3)

É perceptível que, se na proposta inicial, a concepção do trabalho pedagógico estava assentada na politecnia como princípio orientador de formação humana, conduzida à luz da pedagogia histórico-crítica, a versão atual não traz explícito a concepção teórica que justifique a condução do processo educacional. Assim, ao se eximir de clarificar a concepção que deve nortear o ensino em um currículo em tempo ampliado, a instituição escolar assume a responsabilidade de traçar suas ações, amarradas à proposta pedagógica institucional.

\section{A OFICINA MOMENTO DE LEITURA COMO COMPONENTE CURRICULAR OBRIGATÓRIO: Dilemas e desafios}

A escola possui 12 (doze) turmas, sendo 6 (seis) no horário matutino e 6 (seis) no horário vespertino. Cada turma contém 25 a 30 alunos, contabilizando o total de 285 (duzentos e oitenta e cinco) alunos matriculados. Desse total, 107 (cento e sete) alunos frequentam a instituição em tempo parcial de 4 horas de aula e 178 (cento e setenta e oito) alunos frequentam em tempo integral de 8 horas ou 10 horas diárias ${ }^{3}$. As turmas são divididas conforme o ano que estão cursando, respeitando a grade curricular do curso tanto do integral quanto do parcial.

Após 10 (dez) anos de efetivação da proposta no município, antes do início do ano letivo de 2018, sob a justificativa da necessidade de reorganização do sistema municipal de ensino, as escolas ditas de tempo integral passaram a se organizar com uma flexibilização de opção na matrícula, que pode ser efetivada em tempo integral ou parcial. Logo, a flexibilização acompanha também a Proposta Curricular que preserva os componentes curriculares da Base Nacional Comum Curricular tais como Língua Portuguesa, Matemática, Ciências, Geografia, História e da parte diversificada para todos os alunos

\footnotetext{
${ }^{3}$ A permanência dos alunos no intervalo entre os componentes curriculares da BNCC e das Oficinas Curriculares é opcional No ato da matrícula, o responsável pelos alunos matriculados em tempo integral apontam se a criança permanecerá por 8 horas ou 10 horas diárias na instituição.
} 
matriculados, compreendendo uma carga horária anual de 800 (oitocentas) horas. Aqueles que frequentam a instituição em jornada ampliada tem um acréscimo de 800 (oitocentas) horas das oficinas curriculares, distribuídas conforme demonstra o quadro 1 :

Quadro 1- Demonstrativo da distribuição das Oficinas Curriculares do Projeto Burareiro de Educação em Tempo Integral

\begin{tabular}{|l|c|c|}
\hline \multirow{2}{*}{ Eixos obrigatórios } & $\begin{array}{c}\text { Oficinas Curriculares } \\
\text { contempladas }\end{array}$ & $\begin{array}{c}\text { Carga Horária } \\
\text { Anual }\end{array}$ \\
\hline \multirow{2}{*}{ ESTUDOS ORIENTADOS } & Momento da Leitura & 160 \\
\cline { 2 - 3 } & Matemática Dinâmica & 160 \\
\cline { 2 - 3 } & Informática Educacional & 40 \\
\cline { 2 - 3 } Subtotal & Estudos e Pesquisa & 40 \\
\hline $\begin{array}{l}\text { ATIVIDADES ARTísTICAS } \\
\text { e CULTURAIS }\end{array}$ & $\begin{array}{c}\text { Teatro, Artesanato, Música, } \\
\text { Dança ou Fanfarra }\end{array}$ & 160 \\
\hline Subtotal & $\mathbf{4 0 0}$ \\
\hline $\begin{array}{l}\text { ATIVIDADES ESPORTIVAS } \\
\text { e MOTORAS }\end{array}$ & $\begin{array}{c}\text { Recreação e Jogos ou } \\
\text { Ginástica }\end{array}$ & 120 \\
\hline Subtotal & $\mathbf{1 6 0}$ \\
\hline \multirow{2}{*}{ SAÚDE EDUCACIONAL } & $\begin{array}{c}\text { Higienização Corporal e } \\
\text { Saúde Físico-mental }\end{array}$ & 40 \\
\hline Subtotal & $\mathbf{1 2 0}$ \\
\hline EDUCAÇÃO ALIMENTAR \\
e AMBIENTAL & Horta Escolar e Jardinagem & 80 \\
\cline { 2 - 2 } & Cuidados com o Lixo & $\mathbf{4 0}$ \\
\hline Subtotal & $\mathbf{4 0 0}$ \\
\hline Total & $\mathbf{8 0 0}$ \\
\hline
\end{tabular}

Fonte: Manual do Projeto Burareiro de Educação em Tempo Integral. Dados organizados pelas autoras.

Ao se observar a distribuição da carga horária nas atividades que contemplam as oficinas curriculares, embora o manual do Projeto de Educação Integral (2013) estudado apresente as mesmas como atividades extracurriculares para o desenvolvimentos de ações artísticas, culturais, comunicação (mídias), saúde e a vivência de situações como elementos essenciais para o aprimoramento pessoal, comunitário, social e cultural do aluno, nota-se que incide sobre as mesmas o destino de $50 \%$ da carga horária das atividades às 
oficinas diretamente relacionadas aos conhecimentos da BNCC: Momento de Leitura, Matemática Dinâmica, Informática Educacional e Estudos e Pesquisas.

Entretanto, essa organização é intencional, uma vez que "[...] os programas compensatórios têm, sobretudo, complementado o currículo hegemônico, adicionando atividades extras ao ensino em pequenos grupos e áreas centrais do conhecimento convencional - principalmente Matemática e Língua Portuguesa" (CORNNELL, 2013, p. 30), em detrimento às ações que deveriam estar diretamente preocupadas com a formação integral do sujeito.

O manual norteador do Projeto justifica a necessidade da carga horária desses componentes curriculares como um mecanismo de recuperação das dificuldades apresentadas em sala de aula, quando expõe:

Para os alunos que dela necessitarem, a recuperação paralela dar-se-á no horário oposto/inverso podendo acontecer nos horários paralelos aos estudos orientados, nas atividades do Momento da Leitura, da Matemática Dinâmica e de Estudo e Pesquisa, com atendimento específico nos objetivos não alcançados em cada componente curricular pelos estudantes (SEMED, 2013, p. 43).

Os objetivos de uma escola em tempo integral, que deveria voltar-se para propiciar o desenvolvimento do sujeito em suas condições individuais e sociais, com atividades que atendesse suas necessidades inerentes à saúde, higiene, alimentação, arte, cultura, convivência, continua a privilegiar componentes curriculares que ideologicamente fariam com que os alunos avançassem, fortalecendo a hegemonia de certos conteúdos em relação a outros, distante de considerar o ato educativo como consequência de múltiplos fatores.

\section{A CONCEPÇÃO DE LEITURA NOS DOCUMENTOS INSTITUCIONAIS}

Ao se propor investigar o componente curricular Momento de Leitura, buscou-se compreender o pressuposto que conduz o desenvolvimento da oficina na instituição. Para isso, parte-se do pressuposto que ao se referir à leitura, muitos são os conceitos que intencionalmente ou não são atribuídos ao ato de ler. Dentre eles, destaca-se o conceito de leitura, apresentado por Martins (2006, p. 22) que afirma:

O conceito de leitura esta geralmente restrita a decifração da escrita, sua aprendizagem, no entanto, liga-se por tradição ao processo de formação global do 
indivíduo, à sua capacitação para o convívio e atuações social, política, econômica e cultural.

Desse modo, a leitura envolve elementos que vão além do fato de decifrar a escrita. Assim, “[...] aprender a ler é uma questão de aprender a reconhecer os aspectos representados graficamente e a inferir os aspectos do sentido para os quais não há representação gráfica alguma" (OLSON, 1997, p. 288)

Ler é atribuir sentido aquilo que é lido. $\mathrm{O}$ ato de ler se efetiva quando produz no sujeito a capacidade de associar a tradução da escrita às relações que estabelece com o meio e com os elementos culturais. Para Foucambert (2008), o ato de ler é uma atividade humana que está inscrita no interior de um projeto maior, que envolve a compreensão daquilo que se lê aplicado a um contexto. Esse ato, para o autor, se dissociado de intenção, não existe, uma vez que o objetivo da leitura não é de reconhecer ou nomear signos, palavras, mas de compreendê-la em um contexto maior.

Assim, pode-se afirmar que um mesmo texto, ao ser decifrado por sujeitos diferentes, ganha significados diferentes, conforme as vivências de cada um, uma vez que o texto é "[...] uma ponte entre o leitor e o conhecimento, a reflexão a reordenação do mundo objetivo, possibilitando-lhe no ato de ler, atribuir significado ao texto e questionar tanto a própria individualidade como o universo das relações sociais" (MARTINS, p. 66).

Neste sentido, o trabalho pedagógico voltado a formação de leitores deve ir além à decodificação de sinais gráficos. Deve possibilitar ao aluno interpretar e relacionar o lido com o mundo que o rodeia, com suas vivências.

Em via de compreender o significado atribuído à leitura na proposta pedagógica da instituição analisada, recorreu-se aos documentos institucionais: o PPP, o planejamento anual da disciplina, além das observações realizadas na instituição e das aulas que subsidiaram a compreensão da temática estudada.

Não se encontrou, especificamente, uma definição para o componente curricular Momento de Leitura no PPP da escola. Como este está diretamente interligado à área de Linguagem, Códigos e suas Tecnologias, o documento apresenta:

O objetivo maior é que nossos alunos se tornem leitores e escritores competentes, neste contexto se faz necessário o trabalho com os mais diferentes gêneros 
textuais, refletir sobre seus diferentes usos sociais expressando-se corretamente de forma oral e escrita no seu cotidiano, revisando os próprios textos e valorizando a leitura como fonte de fruição estética, entretenimento e cultura e a escrita, como registro e oralidade (PPP, p. 83).

Conforme os apontamentos encontrados no PPP, o ato de ler e escrever aparecem em um mesmo contexto, entrelaçados, como mecanismo de formação competente do sujeito. No entanto, o trato pedagógico para o ensino da leitura e da escrita tem como centralidade, no documento, propiciar o contato do sujeito com os diferentes gêneros textuais e a reflexão sobre o uso social da linguagem e se expressar de forma oral ou escrita. Neste contexto, nota-se que o tratamento atribuído à leitura e a escrita prescrita visa a um trabalho pragmático, cujas manifestações de fenômenos oriundos das experiências e vivências são desconsideradas com a justificativa de ensinar o aluno a expressar-se de acordo com a norma culta, apresentada como "correta".

\section{ORGANIZAÇÃO DA OFICINA MOMENTO DE LEITURA E FATORES QUE IMPLICAM NA PRÁTICA PEDAGÓGICA}

Ao se analisar o plano de ensino da oficina Momento de Leitura, buscou-se encontrar elementos que evidenciasse a dimensão atribuída ao ensino do ato de ler e os subsídios que amparam as mediações e dão concretude às ações.

Neste estudo, pode-se constatar que o plano de ensino de $1^{\underline{O}}$ ao $5^{\underline{0}}$ Ano da oficina Momento de Leitura segue as orientações prescritas pela Secretaria Municipal de Educação para o ensino de Língua Portuguesa. Em relação aos conteúdos anunciados, estes englobam: a diferenciação dos gêneros textuais, a produção escrita direcionada, no entanto, dentre os quatro bimestres estão presentes a preocupação com o estudo das classes gramaticais, ortografia e sinais de pontuação.

Quanto aos mecanismos que dão suporte ao trabalho direcionado à leitura, o plano de ensino prevê como procedimentos: o uso de atividades impressas, jogos pedagógicos, recortes de revistas e jornais, reescrita de textos, interpretação de textos. Embora a escola dispunha de um Laboratório de Informática Educacional que no momento da pesquisa dispunha de 9 micro- 
computadores com mais de 10 anos de uso, nota-se que a possibilidade de utilização desse recurso midiático sequer é cogitada.

No decorrer das observações, pode-se constatar alguns desafios que escola enfrenta e que se transforma em elementos dificultadores na efetivação da oficina Momento de Leitura, além de refletir no desenvolvimento de todas as atividades do contraturno, comprometendo, assim, a eficiência de uma proposta de educação integral.

De acordo com Cavaliere (2006, p. 1022), "[...] além de definições curriculares compatíveis, toda uma infraestrutura precisa ser preparada do ponto de vista de espaços, dos profissionais e da organização do tempo". Embora não sejam poucos os desafios apreendidos no decorrer da pesquisa, priorizou-se alguns fatores por serem vistos como essenciais ao se tratar de uma instituição que vivencia uma proposta pedagógica de ampliação do tempo e do currículo, por considerar esses elementos como aspectos centrais a serem considerados. Esses fatores foram organizados e apresentados em três categorias definidas durante a pesquisa, que são: recursos humanos e formação docente, integração curricular e espaços e financiamento do ensino integral.

\section{a) Recursos humanos e formação docente}

Ao discutir sobre uma instituição que oferece o ensino em tempo integral, não há como desconsiderar os recursos humanos e os profissionais que lidam diretamente com a organização do trabalho pedagógico ou que subsidiam as ações para que elas ocorram.

Dentre os profissionais especificados na Proposta do Projeto Burareiro de Educação em Tempo Integral, pode-se verificar que a ampliação do tempo de permanência dos alunos na escola e consequentemente o aumento da demanda em serviços não foi subsidiado pelo número de servidores de apoio, como as merendeiras e zeladoras, que são essenciais para a manutenção da escola.

Nota-se que a carência de recursos humanos tem dificultado o desenvolvimento do trabalho na instituição, por gerar o aumento dos serviços. Consequentemente, isso tem elevado o número de licenças médicas em decorrência da sobrecarga de trabalho. A proposta inicial e a atual preveem 
também o atendimento de profissionais da saúde junto aos alunos, tais como: psicólogos, médicos e dentistas, mas em nenhum momento desde a implantação da proposta esta previsão se efetivou.

Outro elemento visto como indispensável na ampliação do tempo e do currículo escolar é a figura do profissional que organiza as atividades e trabalha diretamente com os alunos. Nas oficinas curriculares estes profissionais são denominados de monitores, estagiários e oficineiros. Para atuar nessa condição, de acordo com o manual do Projeto, faz-se necessário "[...] que comprovem experiência na área de atuação estagiários ou monitores" (SEMED, 2013, p. 24).

Em análise ao quadro de servidores que atuam nas oficinas curriculares na instituição, evidencia-se que os mesmos são estudantes de curso de Licenciatura (Educação Física ou Pedagogia). Embora não se tenha encontrado nos documentos regulamentadores o que distingue os oficineiros, monitores e estagiários, constatou-se que na prática os estagiários trabalham 30 horas semanais e os monitores/oficineiros, 44 horas semanais. Ambos recebem 1 salário mínimo de retribuição pelo serviço prestado.

A seleção desses servidores leva em conta a análise de currículo vitae feita pela instituição contratante ${ }^{4}$. Observou-se que nenhuma formação continuada é oferecida pela Secretaria Municipal de Educação ou pela instituição. Assim, esses sujeitos contam apenas com o acompanhamento o suporte de uma pedagoga que acumula atribuições na escola. Para Cornnell, "[...] se quisermos que haja uma mudança na educação dos sujeitos em situação de pobreza, temos que ver os (as) professores (as) como força de trabalho da mudança" (2013, p. 33).

Diante do cenário encontrado, verifica-se que a proposta de ampliação curricular que propõe, em sua justificativa, a formação cidadã de sujeitos em vulnerabilidade social, usufrui do barateamento da mão de obra profissional, que assume o compromisso de professores, em condições profissionais e salariais diferenciadas. A proposta ainda não cumpre com aquilo que prevê, quando ao longo do período que tem sido desenvolvida, em momento algum conseguiu concretizar a oferta de atendimento voltado à saúde física e mental das crianças, conforme propõe.

\footnotetext{
${ }^{4}$ Associação de Pais e Professores da escola.
} 


\section{b) Integração Curricular}

Primeiramente, busca-se compreender o sentido filosófico do termo integração no currículo. Para Ciavatta (2012, p. 84) “[...] integrar tem o sentido de completude, de compreensão das partes no seu todo ou da unidade no diverso". Isso implica tratar a educação como uma totalidade social, isto é, nas múltiplas mediações históricas que concretizam os processos educativos. Deste modo, integrar os componentes curriculares da BNCC e as oficinas curriculares, deveria ser uma ação na qual a centralidade deveria convergir em um continuum. A ampliação do tempo escolar, da maneira como acontece na instituição pesquisada, consiste em duas propostas diferentes: a primeira, com os componentes curriculares da BNCC que acontece no espaço físico da instituição, com professores habilitados, que participam de formação continuada. Outra, no contraturno, ministrada por estagiários e monitores.

Pode-se averiguar que não só os planos de ensino não conversam entre si, mas também os sujeitos que organizam e orientam as ações pedagógicas destinadas aos mesmos alunos. A descontinuidade da sequência entre os conteúdos abordados em sala de aula e oficinas curriculares, a ausência de diálogos entre os profissionais, são fatores que podem ser atribuídos à organização institucional e às condições efetivas de trabalho. Sobre isso, são implicações que foram evidenciadas no decorrer da pesquisa:

- Horários de planejamentos de ensino divergentes entre professores dos componentes curriculares da BNCC e estagiários;

- Não há, na organização da rotina da escola, momentos previstos para troca de informações sobre os alunos ou procedimentos de ensino entre os professores e os estagiários e oficineiros;

- Plano de ensino divergentes, entre os conhecimentos da BNCC e oficinas curriculares.

- Aulas das oficinas curriculares e BNCC em espaços e ambientes diferentes.

- Não oferta de formação para oficineiros e estagiários.

Desse modo, ao analisarmos as condições concretas da escola, comparando-as com os aparatos legais e institucionais que alicerçam o ensino, ficam 
evidentes as contradições que refletem na organização e operacionalização curricular, seja por meio do ecletismo metodológico, seja pela carência do direcionamento filosófico e epistemológico. Os desafios acima mencionados corroboram a ideia de que integração curricular seja um engodo, uma mera ampliação do tempo na escola, com uma organização e tratamento pedagógico que contribuem para a manutenção do aviltamento e anacronismo dos conteúdos.

Percebe-se que a preocupação central não está na organização daquilo que será transmitido ao aluno no período integral em que permanecer na instituição, mas em mantê-lo em algum espaço, sobre a vigilância de um adulto e ocupado com algum afazer neste tempo e espaço.

\section{c) Espaços e financiamento do ensino integral}

Outros aspectos que se procurou desvelar no estudo foi como a instituição foi preparada, em termos de infraestrutura, para a ampliação do tempo de permanência de alunos e servidores. A observação empírica e dados documentais apontam que, embora a Secretaria Municipal de Educação tenha previsto com antecedência a implementação da proposta de ampliação do tempo e do currículo nas escolas da rede, sua expansão iniciou sem nenhuma ampliação, reformada ou adequação.

As condições estruturais da instituição investigada, que já eram precárias e insuficientes, com a aglomeração de sujeitos, não pode contar sequer com espaços físicos essenciais, como banheiros, por exemplo, para proporcionar as condições mínimas de higiene e saúde aos sujeitos que permanecem por um período de até 10 horas diárias nesses espaços.

Já em relação aos espaços onde acontecem as oficinas curriculares, estas são desenvolvidas em um clube alugado próximo à escola, que conta com um barracão coberto, 2 banheiros, uma cozinha adaptada e um bebedouro. Além de existir a necessidade do deslocamento dos alunos para outros espaços, as condições de trabalho e de estudos são precárias: falta de mobiliários, utensílios e recursos materiais adequados; o ambiente sequer possui ventiladores. Também o espaço aberto fica propício aos fenômenos de chuva e Sol intenso.

No intervalo entre as atividades da BNCC e oficinas, os alunos permanecem na escola ou no clube. Esse período de 2 (duas) horas são destinados à 
higiene pessoal (banho e higiene bucal), brincadeiras dirigidas pelos oficineiros/estagiários, ou descanso em colchonetes espalhados pelas salas de aula ou no chão do barracão do clube, uma vez que em nenhum dos espaços dispõe de sala ambiente para o descanso.

Outro fator investigado foi o financiamento educacional para o desenvolvimento das atividades em turno ampliado. Para estas instituições, Leclerc e Moll (2012, p. 20) apresentam a discussão que:

As políticas de ampliação de jornada deverão levar à educação em tempo integral, referenciadas pela cobertura do financiamento da educação, conforme o que estabelece o Fundo de Manutenção e Desenvolvimento da Educação Básica e de Valorização dos Profissionais da Educação (Fundeb) - Lei no 11.494/2007. Em seu artigo 10, o tempo integral foi considerado como um dos tipos de matrícula a receber ponderação diferenciada para distribuição proporcional de recursos. Assim, passou a ser considerada como de tempo integral a jornada escolar com duração igual ou superior a sete horas diárias, durante todo o período letivo, compreendendo o tempo total que um mesmo aluno permanece na escola ou em atividades escolares, conforme o artigo 4 o do Decreto no 6.253/2007. Isso representa um grande avanço em relação à modéstia do que foi disposto no art. 34 da Lei no 9.394/1996.

Em relação aos recursos financeiros recebidos, o orçamento financeiro da instituição em tornos de dois programas que são: Programa Nacional de Alimentação Escolar (PNAE), cujo recurso é destinado exclusivamente para a aquisição de gêneros alimentícios para a merenda escolar e, o Programa de Gestão Financeira Escolar (PROGFE), criado em 2011 pelo governo municipal, com o objetivo de dar suporte e apoio à manutenção e desenvolvimento do ensino, este Programa agrega recursos oriundos do FUNDEB e os repasses do Tesouro da União, Estados e Municípios. No entanto, somente em 2017 foi regulamentado um valor diferenciado por aluno para as escolas que atendem em tempo integral: de $\mathrm{R} \$ 5,00$ para $\mathrm{R} \$ 10,00$ por mês por aluno, com repasse bimestral.

Levando em consideração que os alunos matriculados em turno integral diurno recebem 3 refeições - café da manhã, almoço e lanche da tarde acrescidos dos demais gastos com materiais de consumo, limpeza e manutenção, diante da demanda atendida, este recurso é insuficiente, tendo a instituição que fazer certas manobras na tentativa de oferecer o mínimo a muitos. 
Nas observações realizadas, percebeu-se que a instituição enfrenta uma enorme carência de recursos materiais e financeiros. Esta dispunha de apenas uma impressora a laser para realizar a impressão de todo o material utilizado pelos professores. Devido à escassez de condições também de papel sulfite, as impressões de material para sala de aula se resumem às provas bimestrais e bilhetes informativos aos pais e responsáveis.

A instituição também não dispunha de um espaço organizado como referência à leitura, como sala de leitura ou biblioteca escolar. Os poucos livros de literatura infantil que a instituição possui, recentemente foram dispostos na sala da coordenação pedagógica para acesso ou empréstimo aos alunos. No início na pesquisa, estes estavam encaixotados, indisponíveis para uso. Deste modo, nota-se que os inúmeros desafios enfrentados pela instituição para o desenvolvimento de sua proposta pedagógica, refletem diretamente no trabaIho desenvolvido na oficina curricular Momento de Leitura.

\section{CONSIDERAÇÕES PROVISÓRIAS}

Nesta trajetória de pesquisa, iniciou-se com algumas indagações acerca da temática e muitas outras brotaram. Dentre elas: como a escola poderá se tornar referência na formação de sujeitos se aquilo que transmite não se assemelha às condições de dignidade humana?

Dentre o evidenciado neste percurso, percebe-se que a proposta de educação em tempo integral analisada não está inclusa na pauta do governo atual, se é que algum dia se fez presente. Neste contexto, pouco, ou quase nada fora investido em termos de infraestrutura, de espaços, de formação de professores. Mesmo as condições essenciais para os cuidados cotidianos, como a higiene pessoal dos alunos (banho, escovação, alimentação) não tem sido vista. Nota-se que o acréscimo nas despesas gerado com a manutenção da proposta se dá com o recurso disponibilizado pela Secretaria de Educação para a contratação de oficineiros, estagiários e monitores. Assim, a realidade demonstra que a proposta de ampliação de tempo e espaço no currículo, apresentada como uma oportunidade de formação, de cuidados para com a saúde, de resgate da cultura e da história de crianças consideradas em vulnerabilidade social, trata-se do canto da sereia para engambelar a classe trabaIhadora. 
Nesses (des)encontros, a concepção de educação integral que norteia o Projeto Burareiro de Educação em Tempo Integral não tem como centralidade o desenvolvimento das múltiplas potencialidades do sujeito. A ampliação do currículo é posta como uma possibilidade de recuperação aos alunos que apresentam dificuldades em Língua Portuguesa e Matemática, reforçando a hegemonia que esses componentes curriculares possuem. Prevalece o mínimo do tempo/espaço destinado ao desenvolvimento da criatividade, da arte, das manifestações culturais, do comunitário.

Ao se ter como pressuposto que o ato de ler é uma ação que vai além da decodificação de signos escritos, assumindo o modo subjetivo de interpretar e estabelecer conexões com mundo, o enfoque dado no trabalho observado reduz-se à preocupação em propiciar ao aluno a compreensão dos padrões da norma culta, sem oportunizar as discussões de linguagens outras que fazem parte do cotidiano dos sujeitos, sem respeitar suas normas de comunicação, sem questionar os sentidos que o ato de ler tem representado aos aprendizes. Como sugestão, instigou-se os envolvidos nesta empreitada a avaliarem suas ações, considerando que, mesmo diante de tantos desafios, faz-se necessário analisar qual a função da leitura? Quem são os alunos leitores? O que leem? Como o trabalho com a leitura pode se tornar mais atrativo aos alunos? De que modo pode-se potencializar a função da leitura nesta instituição?

Essa desconexão também é percebida não só no currículo, mas também dentre quem organiza o trabalho pedagógico. Elencam-se fatores dificultadores da interação entre os sujeitos da escola, entre os componentes curriculares, entre os tempos e os espaços. No entanto, não se consegue vislumbrar perspectivas de mudanças futuras que possam contribuir para a melhoria dessa problemática. Percebe-se que, embora haja um grande esforço por parte da gestão escolar atual, em manter a ampliação do tempo escolar na instituição, nota-se o distanciamento temporal e pedagógico representado por uma proposta dual para o sujeito aprendiz e para o sujeito responsável por organizar a aprendizagem.

Neste enredo, compreende-se que a transformação carece da efetivação de políticas educacionais que estejam alicerçadas em elementos que municiem os sujeitos e os encorajem em direção às mudanças, que os desafiem não somente a decodificar, mas a interpretar signos, fatos, vida. Para isso, faz-se urgente que a formação propiciada por uma ampliação do tempo e do currículo 
aconteça em condições de acesso aos bens culturais e que o espaço da escola favoreça a disseminação, a produção de conhecimentos e o reconhecimento do aluno como sujeito histórico e social. Manter os filhos da classe trabalhadora sobre os cuidados de um adulto por 8 ou 10 horas diárias, não é garantia de municiá-los de conhecimentos diante da escassez de uma concepção de educação transformadora, de financiamento educacional, da insuficiência de profissionais e o restrito investimento na formação de professores que se veem desprovidos de condições para lidarem com esta empreitada.

\begin{abstract}
Resumo: Este trabalho resulta de uma pesquisa acerca do desenvolvimento da oficina Momento de Leitura, como componente curricular de $1^{\circ}$ ao $5^{0}$ Ano do Ensino Fundamental, em uma instituição de ensino em tempo integral no município de Ariquemes (RO). Norteada pelas indagações: qual a concepção de educação integral que norteia a implantação do projeto na rede municipal de ensino? Quais as condições efetivas em que a oficina curricular Momento de Leitura tem sido desenvolvida na instituição analisada?, o objetivo da pesquisa conduziu à análise de fatores que implicam na organização escolar e no desenvolvimento do trabalho pedagógico da oficina Momento de Leitura. Quanto aos procedimentos, esta configura-se como uma pesquisa documental e recorre à observação empírica para subsidiar a compreensão dos fenômenos. A coleta de dados compreendeu a análise dos documentos que normatizam e norteiam a política de ampliação do tempo escolar na rede municipal de ensino, além da análise de documentos e registros institucionais e a observações das aulas no decorrer do $2^{\underline{o}}$ semestre do ano letivo de 2018. Apreende-se que ampliar o tempo escolar, requer além de uma concepção transformadora de educação. Entretanto, implica: condições de infraestrutura, formação profissional, financiamento educacional e considerar os alunos sujeitos históricos.
\end{abstract}

Palavras-chave: Oficina Momento de Leitura. Currículo. Ampliação do tempo escolar.

\begin{abstract}
This work results from a research about the development of the Momento de Leitura workshop as a curricular component from 1st to 5th Year of Primary Education in a full-time teaching institution in the municipality of Ariquemes (RO). Based on inquiries: what is the concept of integral education that guides the implementation of the project in the municipal school network? What are the effective conditions in which the Reading Moment curriculum has been developed in the analyzed institution?, the objective of the research led to the analysis of factors that imply in the school organization and in the development of the pedagogical work of the Momento de Leitura workshop. As for the procedures, this is configured as a documentary research and uses the empirical observation to subsidize the understanding of the phenomena. Data collection included the analysis of the documents that regulate and guide the policy of expanding school time in the municipal school network, as well as the analysis of documents and institutional records and observations of classes during the second semester of the 2018 school year. It is understood that extending school time requires, besides a transformative conception of education. However, it implies: conditions of infrastructure, professional training, educational funding and consider the students historical subjects.
\end{abstract}

Keywords: Workshop Moment of Reading. Curriculum. Expansion of school time.

\title{
REFERÊNCIAS
}

ARIQUEMES, Projeto político-pedagógico. SEMED: Ariquemes (RO) 2017.

BRASIL. Constituição (1988). Constituição da República Federativa do Brasil de 1988. Disponível em: http://www.planalto.gov.br/ccivil_03/constituicao /ConstituicaoCompilado.htm. Acesso em: 15 set. 2018. 
BRASIL. Lei de diretrizes e bases da educação nacional. Lei n 9394, de 20 de dezembro de 1996.

BRASIL. Plano nacional de educação 2014-2024. Lei no 13.005, de 25 de junho de 2014, que aprova o Plano Nacional de Educação (PNE) e dá outras providências - Brasília: Câmara dos Deputados, Edições Câmara, 2014.

BRASIL. Lei n. 9.394, de 20 de dezembro de 1996. Lei Diretrizes e Bases da EducaçãoNacional. Disponível em: http://www.planalto.gov.br/ccivil_03 /leis/l9394. htm. Acesso em: 15 set. 2015.

BRASIL. Lei no 13.005, de 25 de junho de 2014. Aprova o Plano Nacional de Educação (PNE) e dá outras providências. Diário Oficial da União [da] República Federativa do Brasil, Brasília, 26 jun. 2014.

CAVALIERE, Ana Maria. Tempo de escola e qualidade na educação pública. Educação e Sociedade, Campinas, v.28, n. 100, p. 1015-1035, out. 2007. Disponível em: http://www.scielo.br/pdf/ es/v28n100/a1828100.pdf. Acesso em: 30 out. 2018.

CONNELL, Robert. Pobreza e educação. In: Gentili, Pablo (Org.). Pedagogia da exclusão: crítica ao neoliberalismo em educação. 19. ed. Petrópolis: Vozes, 2013. p. 11-40.

FOUCAMBERT, Jean. Modos de ser leitor: aprendizagem e ensino da leitura no ensino fundamental. Curitiba: Editora UFPR, 2008.

LECLERC, Gesuína de Fátima Elias; MOLL, Jaqueline. Programa Mais Educação: avanços e desafios para uma estratégia indutora da Educação Integral e em tempo integral. Educar em Revista, Curitiba, Brasil, n. 45, p. 91-110, jul./set. 2012. Editora UFPR. Disponível em: Disponível em: www.scielo.br. Acesso em: 10 set. 2018.

MACIEL, Antônio Carlos; BRAGA, Rute Moreira; RANUCCl, Adriana Martins Carneiro. Projeto burareiro de educação integral: original. 1. ed. Porto Velho: Temática Editora, 2016.

MARTINS, Maria Helena. O que é leitura. 19. ed. São Paulo: Ed. Brasiliense, 2006. Coleção: Primeiros passos; 74.

Marx; Karl. Instruções para os delegados do conselho central provisório. Lisboa: Avante Edições, 1982.

OLSON, David. O mundo no papel: as implicações conceituais e cognitivas da leitura e da escrita. Tradução Sérgio Bath. São Paulo: Ática, 1997.

SECRETARIA MUNICIPAL DE EDUCAÇÃO DE ARIQUEMES (RO). Projeto Burareiro de educação integral. Ariquemes: SEMED, 2013.

Recebido em Novembro de 2020

Aprovado em Março de 2021 